\title{
JOMz The Magazine Talks with 2021 TMS President Ellen Cerreta
}

\section{Kelly Zappas}

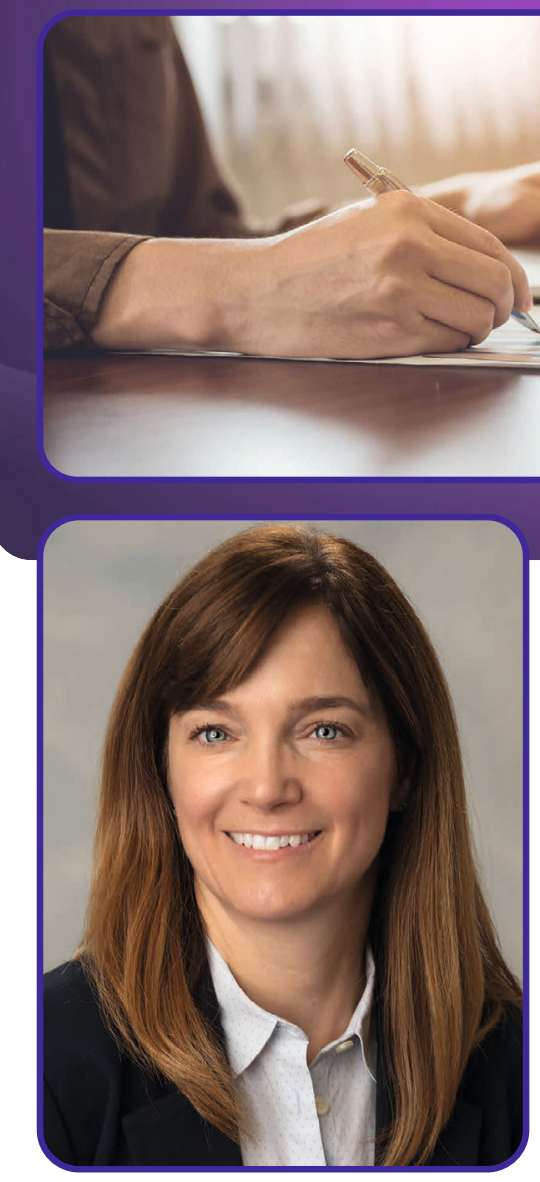

Ellen Cerreta

\section{"[Holding MS\&T21 in}

person] proved that we are all still here and we can adapt to the current challenges of the pandemic."

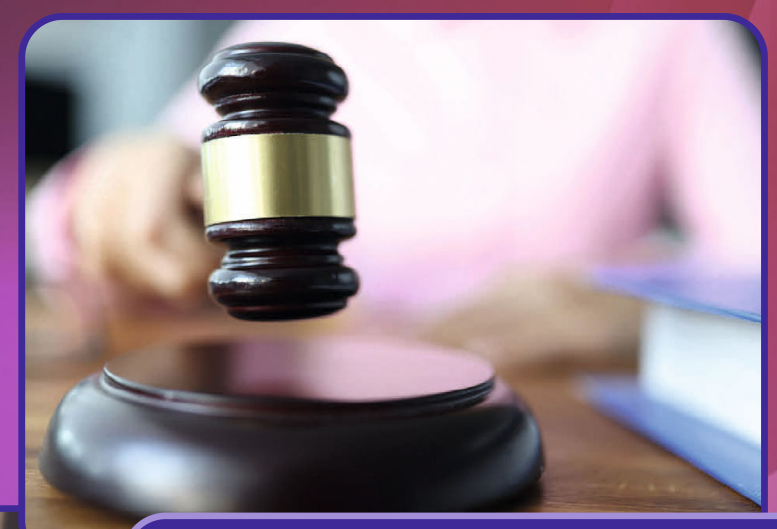

Editor's Note: Ellen Cerreta completed her term as 2021 TMS President at the TMS 2022 Annual Meeting \& Exhibition (TMS2022), February 27-March 3, 2022, in Anaheim, California. In this conversation with JOM: The Magazine, Cerreta reflects on her experiences as TMS President and discusses her hopes for the Society's future.

JOM: As the world continued to grapple with the COVID-19 pandemic and its ripple effects, what unique challenges did you face during your year as TMS President in 2021?

Cerreta: For me, it seems that a professional society does things better in person. A lot gets lost when you don't have the ability to meet face to face. So I think a special challenge was this: how do we work as a board of directors-and, for me, in a leadership role on the Board of Directors-to ensure that we are still delivering services to members. That was probably the biggest challenge and something that was important to me.

JOM: Your TMS presidential term began with the first fully virtual TMS Annual Meeting \& Exhibition in March 2021. What was that experience like for you? How do you think that event benefited our members?

Cerreta: While a virtual event, I think, was not as appealing as an in-person event and there was a sentiment of "we miss being together in person," I think it was important just to have an event like TMS2021 Virtual. There was still a need to be able to share your research, to be able to peer review each other's research, and to have an opportunity to present work. We were missing those opportunities. Even if it wasn't ideal, it was still important to provide that opportunity for our members.

JOM: Later in the year, our Society returned to in-person meetings with MS\&T21 in October. How was that experience after such a long time apart? How did our members respond?

Cerreta: Even knowing it was going to be limited attendance and that a lot of things couldn't be like they used to be, it was so worth it. It was worth it to show that we could come back together and keep everybody safe. It proved that we are all still here and we can adapt to the current challenges of the pandemic. 
"If TMS2022 ends up moving the needle closer to where we want to be, I will feel like I did my job."

\section{"As far as becoming} a more international presence in the materials profession and being that goto Society, I'm really eager to see how we start to leverage the fact that we've learned how to connect in a virtual world."
JOM: In your inaugural speech at TMS2021 Virtual, you said that the part of this presidential role that you were most excited by is the ability to advance the implementation of the TMS Aspires strategic plan. What are some ways you think we've progressed on those goals as a Society in the past year?

Cerreta: We introduced the TMS Aspires Strategic Plan in late 2018. Of course, we're not making the kind of progress I would have hoped for back when I was sitting on the Board and involved in that strategic planning. With that said, I'm really pleased that the TMS 2022 Annual Meeting \& Exhibition (TMS2022) is co-located with the Fourth Summit on Diversity in the Minerals, Metals, and Materials Professions (DMMM4). That directly ties to goal one of our strategic plan with regards to diversity, equity, and inclusion.

I am also really pleased that we are continuing to expand programming in newer areas of interest to members regarding advances in the use of artificial intelligence and machine learning in materials science. I'm looking forward to continued growth in areas like advanced manufacturing programming. I think that really speaks to our goals under the strategic plan.

One of the things that happened during COVID is that we showed that we can use some of the tools that enable broader engagement worldwide. As far as becoming a more international presence in the materials profession and being that go-to Society, I'm really eager to see how we start to leverage the fact that we've learned how to connect in a virtual world.

\section{JOM: What do you consider to be your greatest contribution as TMS President?}

Cerreta: I think my job changed almost instantly when the pandemic hit. I viewed my job as keeping the Society operating under these new circumstances. Early in 2020, it was hard to understand what TMS was going to look like on the other side of this pandemic, but we needed to make sure we would still be here when we got to the other side.

I think that Tom Battle [2020 TMS President], Jim Foley [2019 TMS President], and now Jud Ready [2021 TMS Vice President] and I have been able to lead a Board of Directors in lockstep with TMS staff and that allows us to start asking ourselves some new questions. Now that we are starting to come out of the pandemic, what do we want to look like? Who are we going to be? The Society may not look exactly the same way it looked before. But the pandemic has allowed our profession to explore a new art of the possible for networking and also taught us what we really value about the traditional ways in which we engaged as a society. There is value in having experienced that.
Cerreta lead the first

in-person TMS Board of Directors meeting in 2021 at the MS\&T21 conference in October.

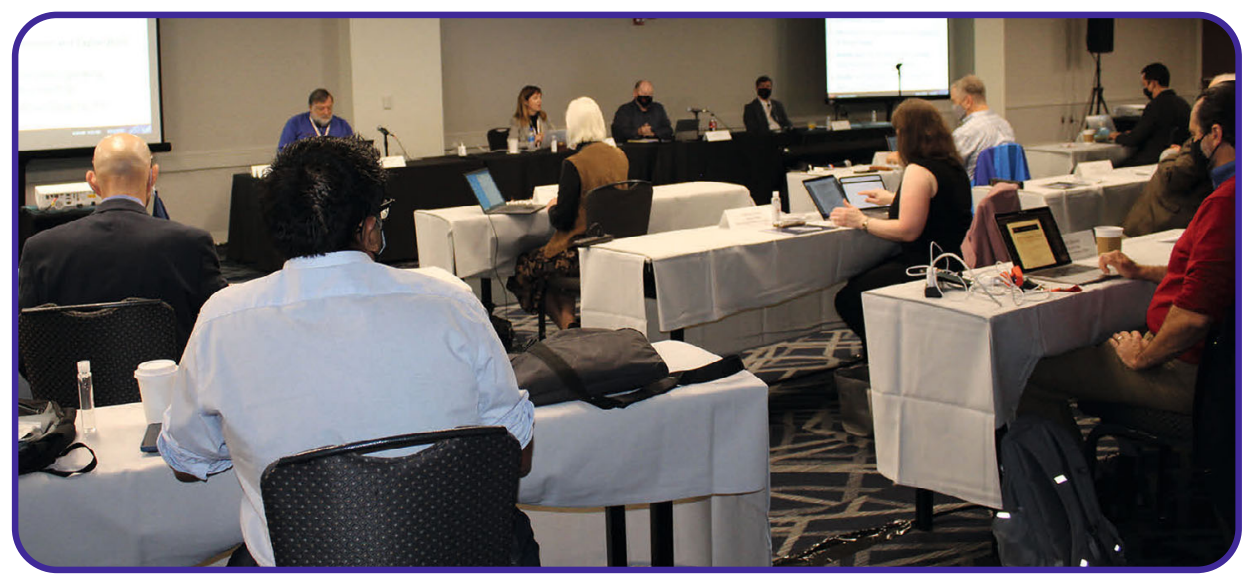


JOM: What have you learned from your presidential experience?

Cerreta: There are several things that got reinforced or validated for me. First, the TMS membership is really an impressive group of scientists, engineers, and generally creative thinkers. They provide a lot of terrific ideas-almost too many to act on. It was almost hard to hear so many good ideas and not have the resources to act on all of them.

Another thing that I knew was important but that was reinforced during this year was really making sure that we were doing things that were responsive to the membership. This isn't a board of directors making decisions about what we think should happen in materials science. We're supposed to be offering a product that enhances the profession. In many places, we were able to do that by offering events virtually during COVID. I think we pushed ourselves to prove that we could actually do something in person by going back to MS\&T. I'm very, very hopeful that, at TMS2022, we get to that next level of engagement. If TMS2O22 ends up moving the needle closer to where we want to be, I will feel like I did my job.

\section{JOM: Is there anything else you'd like to add?}

Cerreta: Despite the fact that this wasn't necessarily the presidential year I thought I was going have, I really am completely honored to have been the TMS president and have been able to play a role in making sure that the Society is healthy. I will be so proud forever to look back on that.

\section{TMS Board of Directors}

\section{OFFICERS}

2022 President

W. Jud Ready

Principal Research Engineer,

Georgia Institute of Technology

2022 Vice President

Brad L. Boyce

Sandia National Laboratories

Past President

Ellen Cerreta

Division Leader, Los Alamos

National Laboratory

Financial Planning Officer

Charles H. Ward

Chief of the Manufacturing and

Industrial Technologies Division,

U.S. Air Force Research Laboratory's

Materials and Manufacturing

Directorate

TMS Secretary (non-voting)

James J. Robinson

Executive Director, TMS

\section{FUNCTIONAL AREA DIRECTORS}

Content Development \&

Dissemination Director/Chair

Judith Schneider

Professor, University of Alabama

at Huntsville

Membership \& Student

Development Director/Chair

Viola L. Acoff

The University of Alabama

Professional Development

Director/Chair

David L. Bourell

Temple Foundation Professor of

Mechanical Engineering,

The University of Texas at Austin

Programming Director/Chair

Timothy Rupert

Associate Professor,

University of California, Irvine

Public \& Governmental Affairs

Director/Chair

Eric N. Brown

Executive Advisor, Los Alamos

National Laboratory

\section{TECHNICAL DIVISION DIRECTORS}

Extraction \& Processing Division

Director/Chair

Christina Meskers

Senior Advisor, Norwegian University

of Science and Technology (NTNU)

Functional Materials Division

Director/Chair

Paul Ohodnicki

Associate Professor,

University of Pittsburgh

Light Metals Division

Director/Chair

Edward Williams

Arconic Technology Center

Materials Processing \&

Manufacturing Division

Director/Chair

Paul Mason

Thermo-Calc Software Inc.

Structural Materials Division

Director/Chair

Suveen Mathaudhu

Colorado School of Mines 